\title{
La regla de decisión clínica Ottawa HSA podría ayudar a detectar pacientes con hemorragia subaracnoidea que debutan con cefalea aguda
}

Ottawa SAH clinical decision rule could help to detect subarachnoid hemorrhage patients presenting with acute headache

Perry y col. JAMA 2013;310(12):1248-55.

\section{Objetivos}

Evaluar la precisión, confiabilidad, aceptabilidad y potencial de refinamiento de tres reglas clínicas en una cohorte de pacientes con cefalea aguda para la detección de hemorragia subaracnoidea (HSA).

\section{Diseño y lugar}

Estudio de cohorte multicéntrico, realizado en diez departamentos de emergencia de hospitales universitarios de Canadá entre abril de 2006 y julio de 2010.

\section{Criterios de inclusión}

Pacientes mayores de 16 años que consultaron por cefalea no traumática con su intensidad máxima alcanzada en la primera hora y puntaje de Glasgow de 15/15.

\section{Prueba de referencia}

Detección de HSA en una tomografía cerebral (TC) sin contraste, presencia de xantocromía en el estudio de líquido cefalorraquídeo (LCR), o presencia de $>1 \times 10^{6} / \mathrm{L}$ hematíes en el último tubo de LCR, con detección de un aneurisma o una malformación arteriovenosa en una angiografía digital cerebral.

\section{Prueba en estudio}

Se administraron tres reglas de predicción clínica. Las variables de la regla 1 fueron: edad $\geq 40$ años, dolor o rigidez de nuca, pérdida de conciencia presenciada 0 inicio durante el ejercicio. Las variables de la regla 2 fueron: edad $\geq 45$ años, llegar en ambulancia, vómitos o presión diastólica $\geq 100 \mathrm{~mm} \mathrm{Hg}$. Las variables de la regla 3 fueron: edad de 45 a 55 años, dolor o rigidez de nuca, llegar en ambulancia o presión sistólica $\geq 160 \mathrm{~mm} \mathrm{Hg}$. Si más de una variable de alguna de las reglas estaba presente se indicaban estudios complementarios para detectar HSA.

\section{Resultados}

Se incluyeron 2.131 pacientes, con detección de HSA en 132 $(6,2 \%)$. La regla 1 tuvo una sensibilidad del 98,5\% (IC 95\% 94,6 a $99,6)$ y una especificidad de $27,5 \%(25,6$ a 29,5$)$ para la detección de HSA. Cuando se agregaron las variables "cefalea en estallido" y "flexión cervical limitada al examen físico" la sensibilidad aumentó al $100 \%(97,2$ a 100,0) y la especificidad bajó al 15,3\% (13,8 a $16,9)$. A esta variante se la denominó regla Ottawa HSA. La precisión del resto de las reglas clínicas se describe en la tabla 1. La regla 1 pasó por alto dos pacientes con HSA, uno de los cuales requirió tratamiento de un aneurisma. La regla 2 no detectó seis pacientes con HSA, tres de los cuales requirieron tratamiento de aneurismas. La regla 3 no detectó cuatro pacientes con HSA, los cuales requirieron tratamiento de aneurismas.

Los médicos interpretaron de forma incorrecta las reglas en un 4,7, 6 y $4,6 \%$ de los casos para las reglas 1,2 y 3 , respectivamente. La interpretación incorrecta de las reglas 1 y 3 hubieran generado que se pasen por alto un caso de HSA en cada regla.

Tabla 1. Sensibilidad, especificidad y valor predictivo negativo de las reglas clínicas evaluadas y de la regla Ottawa HSA para detección de hemorragia subaracnoidea

\begin{tabular}{c|c|c|c|c}
\multirow{2}{*}{ Resultado } & \multicolumn{4}{|c}{ Regla } \\
\cline { 2 - 5 } & $\mathbf{1}$ & $\mathbf{2}$ & $\mathbf{3}$ & Ottawa HSA \\
\hline Sensibilidad \% (IC95\%) & $98,5(94,6 \mathrm{a} 99,6)$ & $95,5(90,4 \mathrm{a} 97,9)$ & 97,0 (92,5 a 98,8) & 100,0 (97,2 a 100,0) \\
\hline Especificidad \% (IC95\%) & $27,6(25,7 \mathrm{a} 29,6)$ & $30,6(28,6 \mathrm{a} 32,6)$ & $35,6(33,6 \mathrm{a} 37,7)$ & $15,3(13,8 \mathrm{a} 16,9)$ \\
\hline Valor predictivo negativo \% & 99,6 & 99,0 & 99,4 & 100,0 \\
\hline
\end{tabular}

\section{Conclusiones}

La regla Ottawa HSA fue la que tuvo la mayor sensibilidad para detectar pacientes con HSA que se presentaron a la guardia con cefalea aguda y examen neurológico normal. Estos hallazgos sólo pueden aplicarse a pacientes con estas características, y se requiere una evaluación adicional para su aplicación en la práctica clínica de rutina.

Fuente de financiamiento: Instituto Canadiense para la Investigación en Salud.

\section{Comentario}

La cefalea es un motivo de consulta frecuente en departamentos de emergencia, generando más de cinco millones de consultas por año en Estados Unidos de Norteamerica', con una incidencia del 1 al $4 \%$ de HSA en esta población ${ }^{23}$. Actualmente la decisión de realizar estudios complementarios para la detección de HSA en pacientes con cefalea depende del criterio del médico tratante, y está basada en el uso de la TC sin contraste y el análisis de LCR, de ser negativa la TC4.

La utilización de algunas de estas reglas clínicas podría reducir el porcentaje de error diagnóstico en HSA, que actualmente es de aproximadamente $5 \%$. El estudio presentó algunas limitaciones menores, se incluyeron pacientes con cefalea de intensidad máxima en una hora, lo que podría diluir la agudeza del cuadro e inducir estudios en pacientes con otras patologías. El 4 al $6 \%$ de los médicos cometieron errores en la aplicación de las reglas clínicas, y esto podría ser más frecuente en la regla Ottawa HSA que incluye más variables de evaluación.

\section{Conclusiones del comentador}

La utilización de reglas clínicas para la evaluación de pacientes con cefalea aguda mostró una alta sensibilidad para la detección de HSA en pacientes con estas características, por lo que podría ser útil la realización de estudios de validación a nivel local.

Manuel Perez Akly [ Servicio de Diagnóstico por Imágenes, Sección Neurorradiología del Hospital Italiano de Buenos Aires sliman. perez@ hospitalitaliano.org.ar ]

Perez Adky M. La regla de decisión clínica Ottawa HSA podría ayudar a detectar pacientes con hemorragia subaracnoidea que debutan con cefalea aguda. Evid Act Pract Ambul. 2016 ;19(2):50. Abr-Jun. Comentado de: Perry JJ, y col. Clinical decision rules to rule out subarachnoid hemorrhage for acute headache. JAMA. 2013;310(12):1248-55. PMID: 24065011.

\section{Referencias:}

1. Vinson DR. Treatment pattems of isolated benign headache in US emergency departments. Annals of emergency medicine 2002;39:215-22.

2. Dhopesh $\vee$ y col. A retrospective assessment of emergency department patients with complaint of headache. Headache 1979; 19:37-42.

3.Leicht MJ. Non-traumatic headache in the emergency department. Annals of emergency medicine 1980;9:404-9.

4. American College of Emergency Physicians. Clinical policy for the initial approach to adolescents and adults presenting to the emergency department with a chief complaint of headache. Annals of emergency medicine 1996;27:821-44.

5. Vermeulen MJ y col. Missed diagnosis of subarachnoid hemorrhage in the emergency department. Stroke 2007;38:1216-21. 